\title{
SIMULAÇÃO DE MODELOS DE REPOSIÇÃO DE ESTOQUES EM UMA CADEIA DE SUPRIMENTOS COM DOIS ESTÁGIOS
}

\author{
Milton Guilherme Forestieri Fernandes \\ Marco Aurélio de Mesquita \\ Departamento de Engenharia de Produção da \\ Escola Politécnica/USP \\ São Paulo - SP \\ fernandes.m@terra.com.br \\ marco.mesquita@poli.usp.br
}

\begin{abstract}
Resumo
Estratégias de gestão de estoques em uma cadeia de suprimentos com dois agentes, um varejista e um fornecedor, são modeladas utilizando-se a simulação por dinâmica de sistemas. Três estratégias principais encontradas na literatura são modeladas: os agentes tomam as decisões de reposição de estoques independentemente e sem compartilhar informações; os agentes compartilham informações, mas tomam as decisões independentemente; as decisões são centralizadas no fornecedor. São simulados casos onde a demanda tem um aumento instantâneo e depois se estabiliza e onde varia aleatoriamente de período a período, independente e identicamente distribuída de acordo com uma distribuição normal. Observa-se que a amplificação da variação dos pedidos do fornecedor em comparação com a variação da demanda no varejista se reduz com o compartilhamento de informações e a centralização das decisões. O método aqui apresentado demonstrou-se bastante eficaz e pode ser usado para simular outras estratégias que não estão sendo analisadas no presente estudo.
\end{abstract}

Palavras-chave: cadeia de suprimentos; gestão de estoques; dinâmica de sistemas.

\begin{abstract}
Inventory management strategies in a supply chain with two agents, a retailer and a supplier, are modeled using systems dynamics simulation. Three main strategies found in the literature are modeled: the agents take inventory replenishment decisions independently without sharing information; the agents share information, but take decisions independently; the decisions are centralized by the supplier. Scenarios where the demand has an instant increase and then stabilizes and where it varies from period to period, independent and identically distributed according to a normal distribution, are simulated. It is observed that the amplification in the supplier orders variation compared with the demand variation at the retailer are reduced with information share and decisions centralization. The method used showed itself to be very effective and could be used to simulate other strategies that are not analyzed in this study.
\end{abstract}

Keywords: supply chain; inventory management; systems dynamics. 


\section{Introdução}

Em produtos padronizados e com demanda regular é comum a utilização da estratégia de produção MTS (“make-to-stock”, produzir para estoque). A principal vantagem desta estratégia é que os produtos são disponibilizados de imediato ao cliente, porém exige que sejam produzidos antes dos pedidos, fazendo com que a produção seja baseada em previsões de demanda. Como estas previsões estão sempre sujeitas a erro, deve-se manter estoques de segurança para que não faltem produtos em períodos em que a demanda é maior do que o previsto. Porém, como a manutenção destes estoques acarreta custos, eles devem ser dimensionados de forma a equilibrar os custos de perdas de vendas e aqueles oriundos da manutenção dos estoques.

A quantidade a ser mantida em estoque, considerando-se um único local, já foi bastante estudada e pode ser encontrada através da solução do problema do "vendedor de jornal" e outros problemas similares e mais complexos. Arrow et al. (1958) e Silver et al. (1998) apresentam uma extensa discussão sobre este assunto.

O problema se complica quando se passa a analisar a manutenção de estoques de segurança ao longo de uma cadeia de suprimentos. Forrester (1961), Sterman (1989) e Lee et al. (1997), dentre outros, estudaram a aplicação dos modelos desenvolvidos para determinar a quantidade ótima de estoques de segurança em uma única instalação em cadeias de suprimentos. Foi detectado que ocorre uma amplificação da variação dos pedidos de um nível da cadeia para o outro, transformando uma variação pequena no ponto de venda em uma variação muito maior nos níveis mais elevados, fazendo com que os estoques atinjam valores bem maiores que o necessário ou gerando faltas de produtos. Esta amplificação é conhecida como efeito chicote ou efeito Forrester. Towill (1996), Anderson (2000) e Umeda (2006) são exemplos de estudos mais recentes.

Clark \& Scarf (1960), Axsäter (1990) e Axsäter (1993) propõe modelos que levam em consideração múltiplos estágios, como é o caso de uma cadeia de suprimentos. São apresentadas abordagens para a identificação de uma política ótima levando em conta o sistema como um todo.

Utilizando a dinâmica de sistemas como ferramenta de análise, vários estudos apontam os benefícios da colaboração e o compartilhamento de informações na cadeia de suprimentos. Wikner et al. (1991) observam os ganhos obtidos com a redução de estágios na cadeia e do tempo de resposta e com a melhoria do fluxo de informações. Disney et al. (1997) identificam os valores ótimos dos parâmetros utilizados no modelo tradicional de Forrester (1961). Mason-Jones e Towill (1997) verificam o valor da velocidade do fluxo de informações na cadeia de suprimentos. De Souza et al. (2000) propõem um modelo de coordenação descentralizada para reduzir a amplificação da demanda. Hong-Minh et al. (2000) observam o impacto do intercâmbio horizontal de estoques. Disney e Towill (2003) identificam as vantagens da utilização da centralização das decisões no fornecedor em uma cadeia de suprimentos. Oliveira (2004) também verifica o valor do compartilhamento de informações. Disney et al. (2006) e Hosoda e Disney (2006) propõem uma política de ponto de pedido que leva à melhoria do desempenho da cadeia.

A partir dos estudos acima citados, é possível encontrar três estratégias principais para a gestão de estoques. Na primeira, as decisões de reposição de estoques são tomadas independentemente pelos agentes que decidem quando e quanto devem comprar ou produzir, sem que consultem um ao outro e sem compartilhar informações. Na segunda, o fornecedor tem acesso à quantidade demandada pelos consumidores no varejista, porém os agentes continuam tomando suas decisões de reposição de estoques independentemente. Por fim, na terceira, as decisões de reposição de estoques são tomadas pelo fornecedor que tem acesso à quantidade demandada pelos consumidores e o nível de estoque no varejista e decide quanto será enviado ao varejista em cada período e quanto será produzido. 
Este trabalho tem como objetivo modelar estas estratégias utilizando a simulação por sistemas dinâmicos para avaliar e comparar o comportamento da variação nos pedidos tanto do varejista para o fornecedor quanto dos pedidos de produção em relação à variação da demanda, assim como a variação nos níveis de estoques ao longo do tempo nas três estratégias. A modelagem e análise destas estratégias já foi realizada em estudos anteriores, porém cada trabalho apresentou apenas uma estratégia. A originalidade deste artigo está na comparação das três estratégias utilizando exatamente o mesmo método. Também é objetivo deste trabalho demonstrar de forma clara a utilização do método de modelagem e simulação para que outras estratégias e outros modelos de cadeia de suprimentos possam ser desenvolvidos, possibilitando novas comparações com as estratégias do presente trabalho.

\section{Dinâmica de sistemas}

Para analisar estas estratégias de reposição de estoques, será utilizada a simulação por dinâmica de sistemas. Esta abordagem de simulação foi criada por Forrester (1961) e depois aperfeiçoada, dentre outros, por Roberts et al. (1983) e Sterman (2000).

De acordo com Roberts et al. (1983), a construção de um modelo de simulação de sistemas dinâmicos deve seguir as seguintes etapas:

1. Definição do modo de referência - Os comportamentos reais das principais variáveis do sistema em estudo para serem posteriormente comparadas com os comportamentos das variáveis simuladas pelo modelo;

2. Elaboração do diagrama causal - O diagrama causal apresenta todas as variáveis pertencentes ao modelo e suas inter-relações. Também apresenta os ciclos de retroalimentação, que são representados com uma seta circular com um sinal negativo ou positivo, de acordo com o tipo de ciclo.

Os ciclos de retro-alimentação são causados pela influência indireta que uma determinada variável causa sobre ela mesma. Caso este ciclo seja positivo, a variável tende a crescer exponencialmente. Caso seja negativo, a variável buscará uma estabilização, porém passando por oscilações.

3. Elaboração do diagrama de fluxo - Neste diagrama, as variáveis são identificadas como níveis, vazões, variáveis auxiliares ou parâmetros, cada tipo com seu símbolo específico. Os símbolos estão ilustrados na tabela 1 . 
Tabela 1 - Símbolos usados nos diagramas de fluxo

\begin{tabular}{|c|c|c|c|}
\hline Símbolo & Significado & Símbolo & Significado \\
\hline & $\begin{array}{l}\text { Nível }- \text { representa } \\
\text { variáveis que se acumulam } \\
\text { ao longo do tempo. }\end{array}$ & $\sum_{W}^{M}$ & $\begin{array}{l}\text { Fonte/sorvedouro } \\
\text { inesgotável } \\
\text { representam lugares onde } \\
\text { a quantidade de material } \\
\text { é teoricamente infinita. }\end{array}$ \\
\hline & $\begin{array}{l}\text { Vazão } \\
\text { variáveis que representa } \\
\text { variações nos níveis. }\end{array}$ & & $\begin{array}{l}\text { Fluxo de materiais - } \\
\text { identifica a direção e o } \\
\text { inter-relacionamento das } \\
\text { variáveis envolvidas no } \\
\text { fluxo de materiais }\end{array}$ \\
\hline & $\begin{array}{l}\text { Parâmetro - representam } \\
\text { variáveis exógenas. }\end{array}$ & & $\begin{array}{l}\text { Fluxo de informações - } \\
\text { identifica a direção e o }\end{array}$ \\
\hline & $\begin{array}{lll}\text { Variável } & \text { auxiliar } & - \\
\text { variáveis } & \text { intermediárias } \\
\text { envolvidas no fluxo de } \\
\text { informações. }\end{array}$ & & $\begin{array}{l}\text { variáveis envolvidas no } \\
\text { fluxo de materiais }\end{array}$ \\
\hline
\end{tabular}

4. Equações - Com a ajuda dos diagramas causal e de fluxo escrevem-se as equações do modelo para os níveis, fluxos e variáveis auxiliares. A evolução no tempo é feita em intervalos discretos DT. Exemplo:

$\mathrm{Nt}=\mathrm{Nt}-1+($ Fet - Fst $) \mathrm{xDT}$

Onde N é o nível, Fe é o fluxo de entrada e Fs o fluxo de saída. Os indicadores t,t-1...indicam o período de tempo.

Os fluxos são funções dos parâmetros e das variáveis auxiliares.

5. Simulações - Por fim são realizadas as simulações. A princípio, a simulação deve retratar o modo de referência, o que indicará que o modelo está adequado para simular a realidade. Posteriormente, pode-se variar os parâmetros com o intuito de construir cenários alternativos ao da situação de referência.

\section{Modelagem}

\subsection{Modelo I - Tomada de decisão independente sem compartilhamento de informações}

O primeiro modelo visa representar o comportamento da dinâmica dos estoques e pedidos na estratégia I, onde os agentes tomam decisões independentemente, sem compartilhar informações.

O modo de referência pode ser observado na figura 1. 


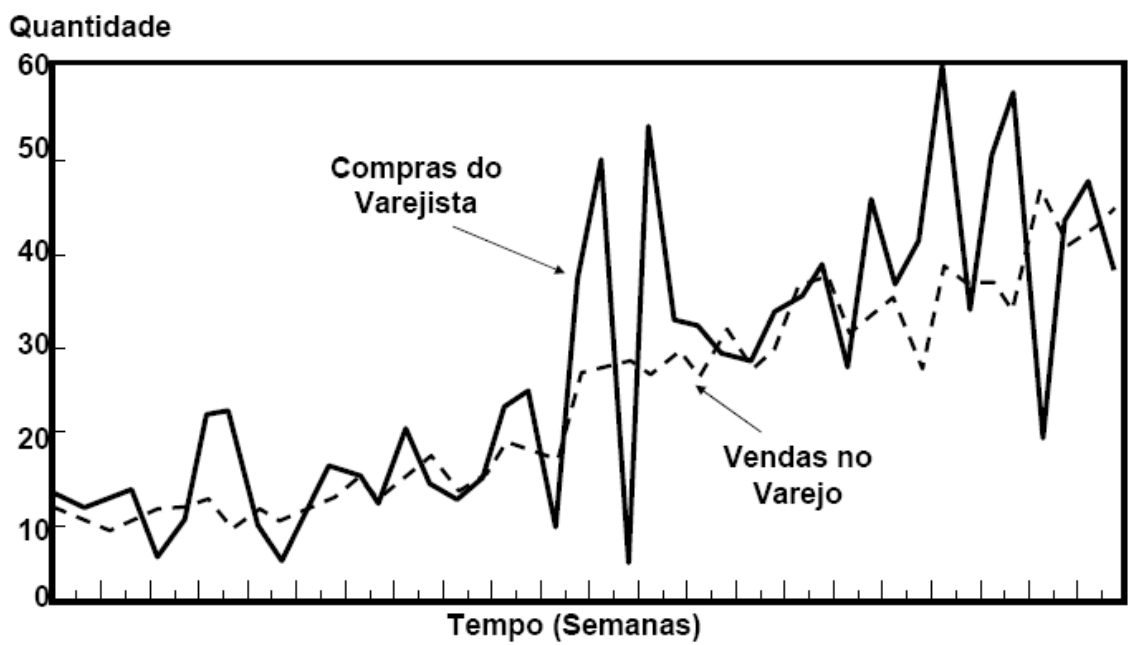

Figura 1 - Modo de referência (efeito chicote) (Lee et al., 1997)

As variáveis relevantes do problema em questão são a demanda, os pedidos de produção e de reposição de estoques na fábrica e no varejista. Estas variáveis devem apresentar um comportamento de amplificação conforme a figura 1. Na figura observa-se que a demanda (vendas no varejo) tem uma variação relativamente mais branda do que os pedidos que coloca ao fornecedor (compras no varejo). O mesmo ocorre em maior intensidade na relação entre os pedidos do varejista com os pedidos de produção no fornecedor.

A segunda etapa da modelagem é a elaboração do diagrama causal, apresentando todas as variáveis envolvidas, suas correlações (o sinal de “+” indica correlação positiva e o “-” correlação negativa) e os ciclos de retro-alimentação (apresentados com uma seta circular com o respectivo sinal positivo ou negativo). O diagrama causal do modelo I é apresentado na figura 2.

No diagrama causal é representado o fluxo de materiais, bem como os fluxos de informações e tomada de decisões. Observa-se no diagrama o fluxo de materiais formado pelo "work in process", produção e estoque fábrica no fornecedor e os pedidos em trânsito, entregas, estoque varejista, consumo e demanda no varejista. Os fluxos de informações e tomada de decisões do varejista são formados pela demanda esperada, a cobertura desejada no varejista, o estoque desejado no varejista, a diferença entre estoque real e desejado no varejista, tempo de ajuste de estoque no varejista e os pedidos. Outro fluxo similar ocorre no fornecedor, formado pelos pedidos esperados, a cobertura de estoque desejada na fábrica, o estoque desejado na fábrica, a diferença entre estoque real e desejado na fábrica, o tempo de ajuste de estoque no fornecedor e os pedidos de produção.

Observam-se também nove variáveis de entrada, que não recebem influência de nenhuma outra: A demanda, o tempo de entrega, o tempo de pedido, o tempo de ajuste na demanda, o tempo de ajuste nos pedidos esperados, o tempo de ajuste de estoques no varejista, o tempo de ajuste de estoques no fornecedor, a cobertura desejada no varejista e na fábrica. Uma distinção importante nestas variáveis de entrada deve ser ressaltada: A demanda e os tempos de produção e entrega são dados externos, ou seja, não podem ser definidos pelos tomadores de decisão. As outras variáveis de entrada são definidas pelo tomador de decisão no varejista e no fornecedor.

É importante observar no diagrama os ciclos de retro-alimentação. No modelo I existem quatro. O primeiro é formado pelas inter-relações entre estoque no varejista, a diferença entre o estoque real e o desejado, os pedidos, pedidos em trânsito e as entregas, sendo um ciclo de retroalimentação negativo, o que significa que existe uma busca por um valor de estabilização, porém 
sujeito a oscilações. O mesmo padrão se observa no ciclo idêntico formado no fornecedor (fábrica) pelo estoque fábrica, diferença entre estoque desejado e real na fábrica, pedidos de produção, "work in process" e produção.

Após a construção do diagrama causal deve-se elaborar o diagrama de fluxo. Para o modelo I o diagrama de fluxo é apresentado na figura 3.

No diagrama de fluxo, as variáveis são definidas como níveis, fluxos e parâmetros. O nível apresenta valores que variam de um período para outro e tem sua variação causada pelos fluxos a eles associados. Caso os fluxos de entrada sejam maiores que os fluxos de saída o nível aumenta, caso contrário o nível diminui. Os fluxos, portanto, definem a intensidade das alterações nos níveis e podem ser influenciados por outras variáveis, podem ser outros fluxos, níveis ou parâmetros. Os parâmetros são as únicas variáveis que não sofrem influência de nenhuma outra.

Podemos observar também que o "work in process", o estoque na fábrica, os pedidos em trânsito, o estoque no varejista, a demanda esperada e os pedidos esperados são níveis, os pedidos de produção, a produção, os pedidos, as entregas, o consumo e as alterações na demanda e pedidos esperados são fluxos e o tempo de produção, tempo de entrega, tempo de ajuste no estoque do varejista, tempo de ajuste no estoque da fábrica, cobertura desejada na fábrica e no varejista e o tempo de ajuste da demanda esperada e de pedidos esperados são parâmetros. Também se observam variáveis auxiliares: O estoque desejado no varejista e na fábrica e a diferença de estoque no varejista e na fábrica.

Neste diagrama é possível ver com maior clareza o fluxo de materiais e o fluxo de informações e tomada de decisões. O fluxo de materiais é apresentado com setas cheias e o fluxo de informações com setas tracejadas.

As "nuvens" nas extremidades dos fluxos são fontes (quando enviam) e sorvedouros (quando recebem) inesgotáveis. 


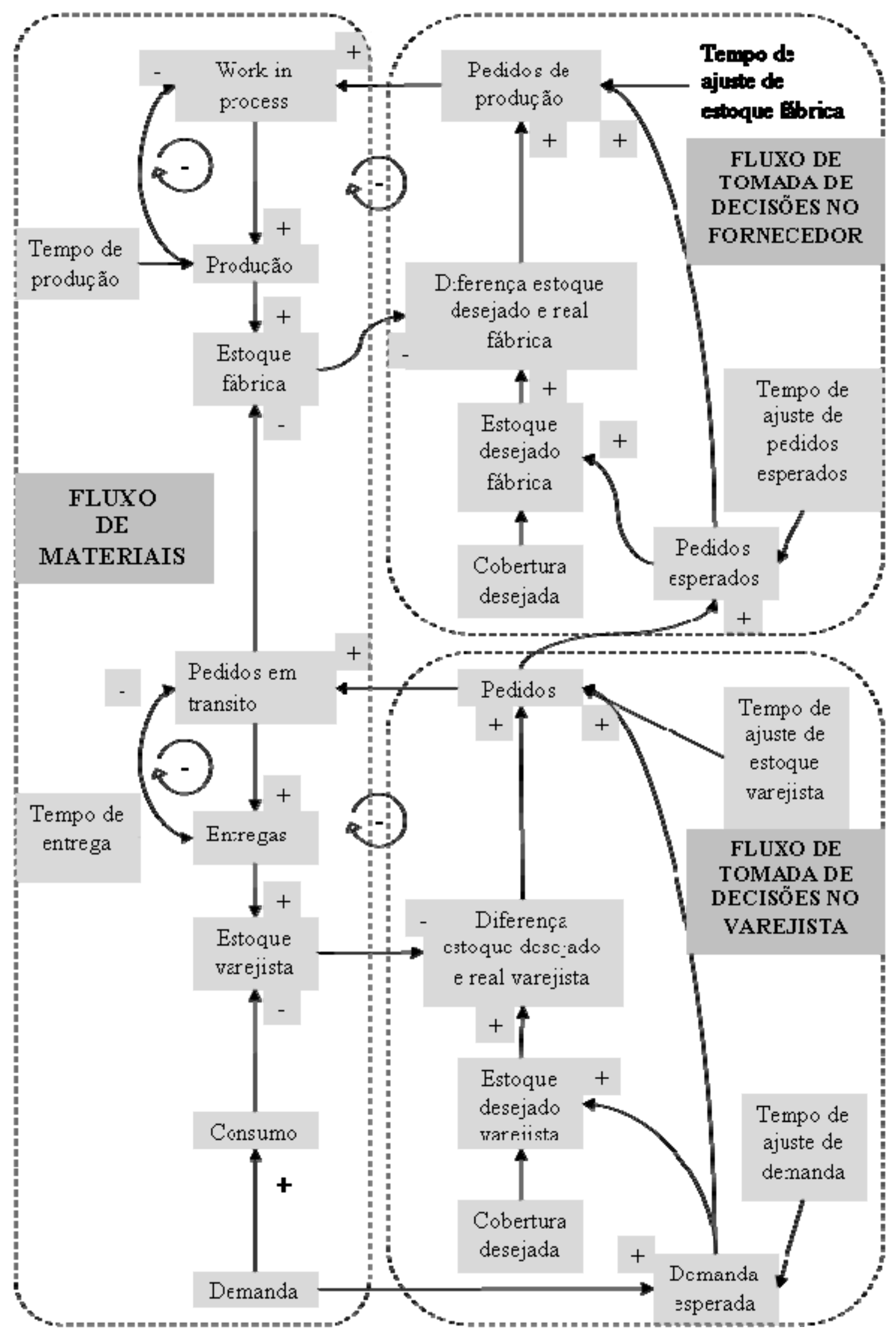

Figura 2 - Diagrama causal do modelo I 


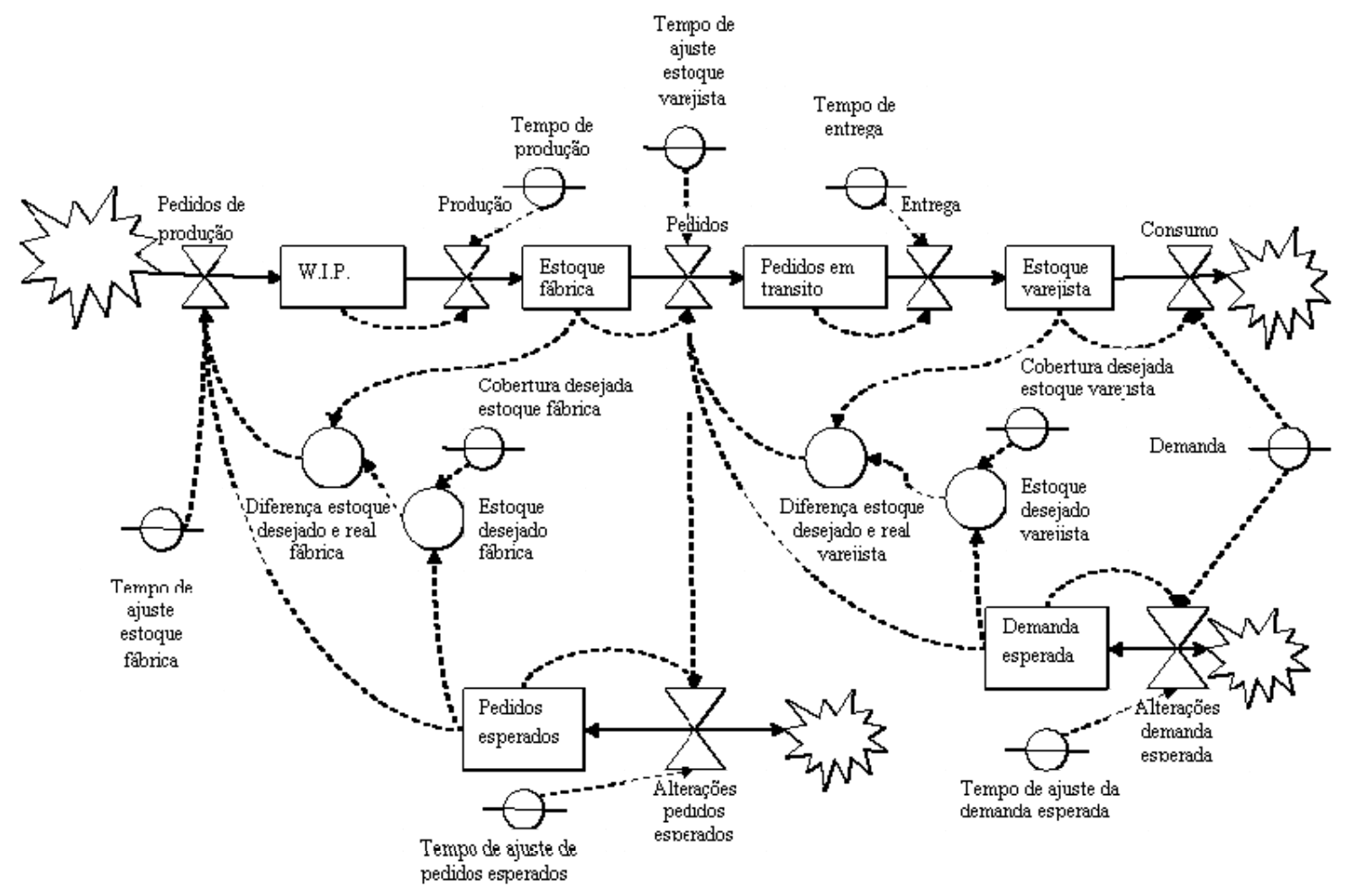

Figura 3 - Diagrama de fluxo do modelo I

Por fim, a partir dos diagramas definem-se as equações do modelo, que são:

$$
\begin{aligned}
& \mathrm{EVj}=\mathrm{EVi}+(\text { Eij }-\mathrm{Cij}) * \mathrm{DT} \\
& \mathrm{Eij}=\mathrm{PTi} / \mathrm{TE} \\
& \mathrm{Cij}=\mathrm{MIN}(\mathrm{Dij}, \mathrm{EVi}) \\
& \mathrm{DEj}=\mathrm{DEi}+\mathrm{ADij} * \mathrm{DT} \\
& \mathrm{ADij}=(\mathrm{Dij}-\mathrm{DEi}) / \mathrm{TA} \\
& \mathrm{EDVi}=\mathrm{DEi}{ }^{*} \mathrm{CDV} \\
& \mathrm{DEVi}=\mathrm{EDVi}-\mathrm{EVi} \\
& \mathrm{Pij}=\mathrm{MAX}(0, \mathrm{MIN}(\mathrm{EFi}, \mathrm{DEi}+\mathrm{DEVi} / \mathrm{TAEV})) \\
& \mathrm{PTj}=\mathrm{PTi}+(\mathrm{Pij}-\mathrm{Eij}) * \mathrm{DT} \\
& \mathrm{EFj}=\mathrm{EFi}+(\mathrm{PRij}-\mathrm{Pij}) * \mathrm{DT} \\
& \mathrm{PRij}=\mathrm{WIPi} / \mathrm{TP} \\
& \mathrm{WIPj}=\mathrm{WIPi}+(\mathrm{PPij}-\mathrm{PRij}) * \mathrm{DT}
\end{aligned}
$$


PPij $=\operatorname{MAX}(0$, PEi + DEFi/TAEF $)$

$\mathrm{PEj}=\mathrm{PEi}+\mathrm{APij}{ }^{*} \mathrm{DT}$

$\mathrm{APij}=(\mathrm{Pij}-\mathrm{PEi}) / \mathrm{TAPDEFi}=\mathrm{EDFi}-\mathrm{Efi}$

$\mathrm{EDFi}=\mathrm{PEi} * \mathrm{CDF}$

Onde:

$\mathrm{EVi}=$ Estoque no varejista em $\mathrm{i}$

$\mathrm{Eij}=$ Entregas no varejista entre i e j

$\mathrm{Cij}=$ Consumo no varejista entre $\mathrm{i}$ e $\mathrm{j}$

Dij $=$ Demanda no varejista entre i e $j$

PTi $=$ Pedidos em trânsito em i

$\mathrm{TE}=$ Tempo de entrega

DE $\mathrm{i}=$ Demanda esperada em $\mathrm{i}$

ADij = Alteração na demanda esperada entre i e j

TA = Tempo de ajuste da demanda esperada

EDVi $=$ Estoque desejado no varejista em $\mathrm{i}$

$\mathrm{CDV}=$ Cobertura desejada no varejista

DEVi $=$ Diferença entre estoque desejado e real no varejista em $\mathrm{i}$

Pij $=$ Pedidos entre i e $\mathrm{j}$

TAEV $=$ Tempo de ajuste estoque varejista

$\mathrm{EFi}=$ Estoque na fábrica em $\mathrm{i}$

PRij = Produção entre i e j

WIPi $=$ Work in process em $\mathrm{i}$

$\mathrm{TP}=$ Tempo de produção

PPij = Pedidos de produção entre i e j

TAEF = Tempo de ajuste estoque fábrica

$\mathrm{PEi}=$ Pedidos esperados em $\mathrm{i}$

APij = Alteração nos pedidos esperados entre i e j

TAP $=$ Tempo de ajuste nos pedidos esperados

$\mathrm{DEFi}$ = Diferença de estoque na fábrica em $\mathrm{i}$

$\mathrm{EDFi}=$ Estoque desejado na fábrica em i

$\mathrm{CDF}=$ Cobertura desejada na fábrica 


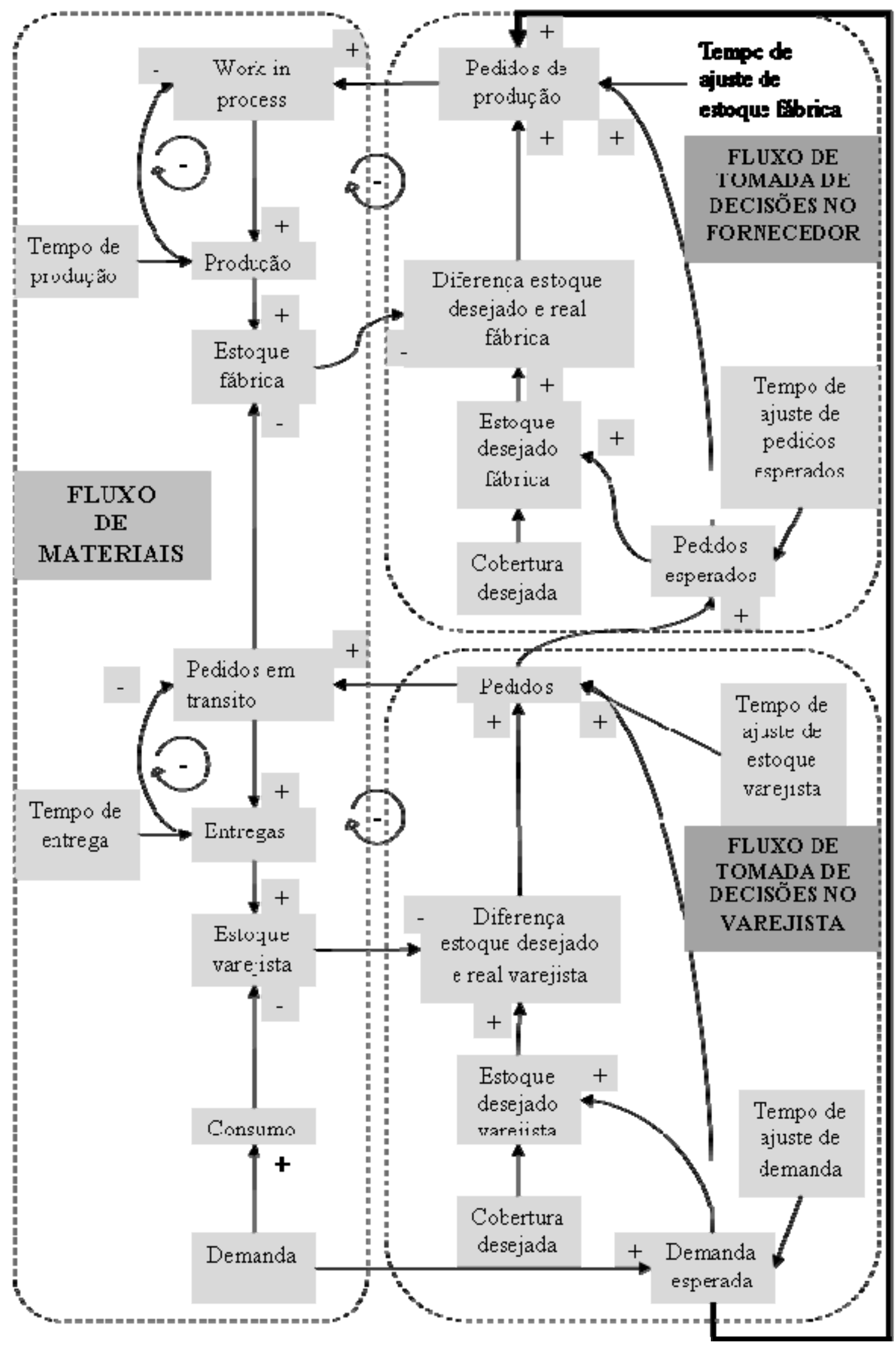

Figura 4 - Diagrama causal do modelo II 


\section{Modelo II - Compartilhamento de informações}

Neste segundo modelo, o fornecedor passa a ter acesso também às informações de demanda do consumidor. Portanto, ele visa verificar a influência do uso dessas informações para a tomada das decisões de reposição de estoques. A exemplo da estratégia do modelo I, ambos os agentes tomam a decisão de reposição de estoque de forma independente.

Como se trata de um modelo normativo e não descritivo como o anterior, não temos um modo de referência. Desta forma, este modelo passa a ser uma variação do primeiro, onde é inserido o aspecto do compartilhamento de informações.

Sendo assim, o diagrama causal do modelo é apresentado na figura 4. É possível notar que ele é bastante semelhante ao modelo dois, onde é possível observar os mesmos fluxos de materiais e fluxos de informações, com o acréscimo do compartilhamento da informação de demanda no consumidor que é representado pela seta ligando a demanda esperada aos pedidos de produção (seta ressaltada), ou seja, na tomada de decisão da quantidade a ser produzida, será levada em conta não apenas os pedidos do cliente esperados, mas também a demanda esperada no ponto de venda.

O diagrama de fluxo do mesmo modelo é apresentado na figura 5. Também é possível observar os mesmos fluxos de materiais e informações e tomada de decisão que no modelo I, com o acréscimo do compartilhamento da informação de demanda no ponto de venda, que é representado pela linha pontilhada ligando a demanda esperada aos pedidos de produção.

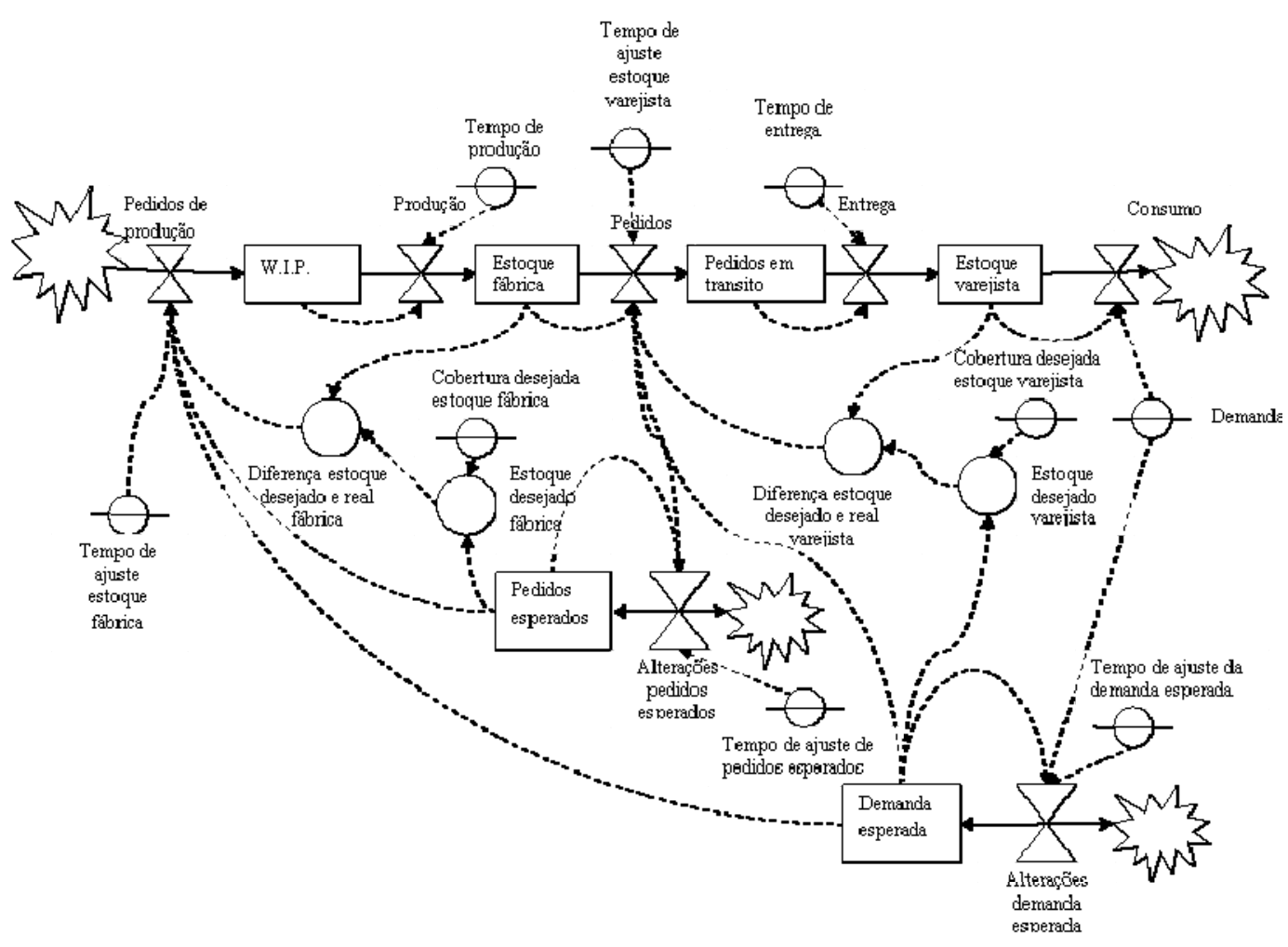

Figura 5 - Diagrama de fluxo do modelo II

Para finalizar a descrição deste modelo são apresentadas suas equações abaixo:

$E V j=E V i+(E i j-C i j) * D T$ 
$\mathrm{Eij}=\mathrm{PTi} / \mathrm{TE}$

$\mathrm{Cij}=\mathrm{MIN}(\mathrm{Dij}, \mathrm{EVi})$

$\mathrm{DEj}=\mathrm{DEi}+\mathrm{ADij} * \mathrm{DT}$

$\mathrm{ADij}=(\mathrm{Dij}-\mathrm{DEi}) / \mathrm{TA}$

$\mathrm{EDVi}=\mathrm{DEi} * \mathrm{CDV}$

$\mathrm{DEVi}=\mathrm{EDVi}-\mathrm{Evi}$

$\mathrm{Pij}=\operatorname{MAX}(0, \operatorname{MIN}(E F i$, DEi + DEVi/TAEV $))$

$P T j=P T i+(P i j-E i j) * D T$

$E F j=E F i+(P R i j-P i j) * D T$

PRij $=$ WIPi/TP

WIPj $=$ WIPi $+(P P i j-P R i j) * D T$

$\mathrm{PPij}=\operatorname{MAX}(0,(1-\mathrm{X}) * \mathrm{PEi}+\mathrm{X} * \mathrm{DE} \mathrm{i}+\mathrm{DEFi} / \mathrm{TAEF})$

$P E j=P E i+A P i j * D T$

$\mathrm{APij}=(\mathrm{Pij}-\mathrm{PEi}) / \mathrm{TAP}$

$\mathrm{DEFi}=\mathrm{EDFi}-\mathrm{Efi}$

$\mathrm{EDFi}=\mathrm{PEi}{ }^{*} \mathrm{CDF}$

Onde:

$\mathrm{EVi}=$ Estoque no varejista em $\mathrm{i}$

Eij $=$ Entregas no varejista entre i e $\mathrm{j}$

$\mathrm{Cij}=$ Consumo no varejista entre $\mathrm{i}$ e $\mathrm{j}$

Dij $=$ Demanda no varejista entre i e $\mathrm{j}$

PTi $=$ Pedidos em trânsito em i

$\mathrm{TE}=$ Tempo de entrega

$\mathrm{DEi}=$ Demanda esperada em $\mathrm{i}$

ADij = Alteração na demanda esperada entre i e j

TA = Tempo de ajuste da demanda esperada

$\mathrm{EDVi}=$ Estoque desejado no varejista em $\mathrm{i}$

$\mathrm{CDV}=$ Cobertura desejada no varejista

$\mathrm{DEVi}=$ Diferença entre estoque desejado e real no varejista em i

Pij $=$ Pedidos entre i e $\mathrm{j}$

TAEV $=$ Tempo de ajuste estoque varejista

$\mathrm{EFi}=$ Estoque na fábrica em i

PRij = Produção entre i e $\mathrm{j}$

WIPi $=$ Work in process em $\mathrm{i}$

$\mathrm{TP}=$ Tempo de produção 
PPij $=$ Pedidos de produção entre i e j

$\mathrm{X}=$ Porcentagem de participação da demanda na colocação do pedido de produção

TAEF $=$ Tempo de ajuste estoque fábrica

$\mathrm{PEi}=$ Pedidos esperados em $\mathrm{i}$

APij = Alteração nos pedidos esperados entre i e j

TAP $=$ Tempo de ajuste nos pedidos esperados

DEFi $=$ Diferença de estoque na fábrica em i

$\mathrm{EDFi}$ = Estoque desejado na fábrica em i

$\mathrm{CDF}=$ Cobertura desejada na fábrica

É possível notar que a única mudança em relação ao modelo I é na equação (29), dos pedidos de produção, que agora envolve uma ponderação entre a demanda esperada e os pedidos esperados e o fator X determina a participação da demanda esperada (assim como (1-X) se refere a participação dos pedidos esperados. $\mathrm{X}$ deve ser maior que zero e menor do que um).

\subsection{Modelo III - Centralização de decisões}

Nesta estratégia, a decisão de reposição de estoques não é mais tomada independentemente pelos agentes e sim centralizada no fornecedor. O fornecedor tem acesso a todas as informações de demanda e posições de estoque.

A exemplo do modelo II, também se trata de um modelo normativo, sendo uma variação do modelo I e tem como objetivo melhorar o desempenho da gestão de estoques na cadeia.

Seguindo o método apresentado, o diagrama causal foi elaborado e pode ser visualizado na figura 6. O fluxo de materiais é o mesmo dos modelos anteriores, formado pelo "work in process", a produção, o estoque na fábrica, os envios para o varejista (que correspondem aos pedidos dos modelos anteriores, porém como neste modelo as decisões de reposição de estoque são tomadas pelo fornecedor, o termo envio é mais adequado), os envios em trânsitos, as entregas no varejista, o estoque no varejista e o consumo.

Já o fluxo de informações é bem diferente dos modelos anteriores, devido à centralização da demanda. Como nos modelos anteriores, existem duas decisões a serem tomadas: Quanto deve ser enviado ao varejista e quanto deve ser produzido a cada período. O fluxo de informações para tomar a decisão de envios para o varejista é formado pela demanda, a demanda esperada, as alterações na demanda esperada, a demanda esperada, o estoque desejado no varejista, a diferença de estoque no varejista e por fim os envios para o varejista. O fluxo de informações para a decisão de pedidos de produção envolve o estoque no sistema, o estoque desejado no sistema, a diferença de estoque no sistema, a demanda, as alterações na demanda esperada, a demanda esperada e por fim os pedidos de produção.

Deve-se observar a diferença na decisão sobre pedidos de produção. Neste modelo, ela é tomada baseada no estoque no sistema, que consiste da soma dos estoques a jusante na cadeia, isto é, o estoque fábrica, os envios em trânsito e o estoque no varejista. Assim como no modelo II ele utiliza as informações de demanda no ponto de venda ao invés dos pedidos do varejista para realizar suas previsões de venda.

As variáveis de entrada são praticamente as mesmas dos outros modelos: $\mathrm{O}$ tempo de entrega e de produção, o tempo de ajuste na demanda esperada, a cobertura desejada no varejista e no sistema e o tempo de ajuste nos estoques no varejista e no sistema. 
Também é possível notar que continua havendo quatro ciclos de retro-alimentação negativos. Os dois ciclos de ajuste de estoque e os ciclos entre "work in process" e produção e entre envios em trânsito e entregas no varejista.

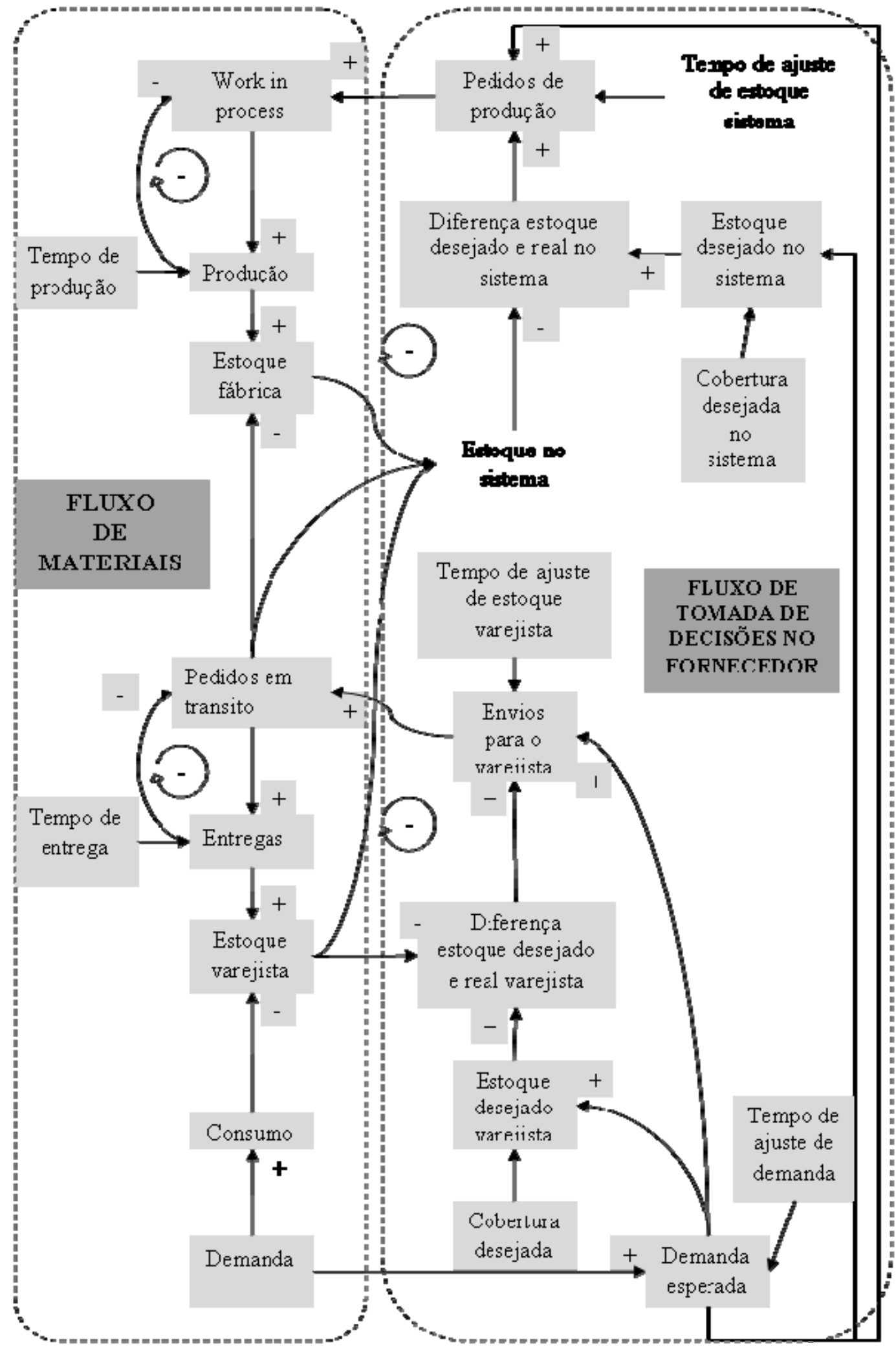

Figura 6 - Diagrama causal do modelo II 
Na figura 7 pode-se observar o diagrama de fluxo do modelo.

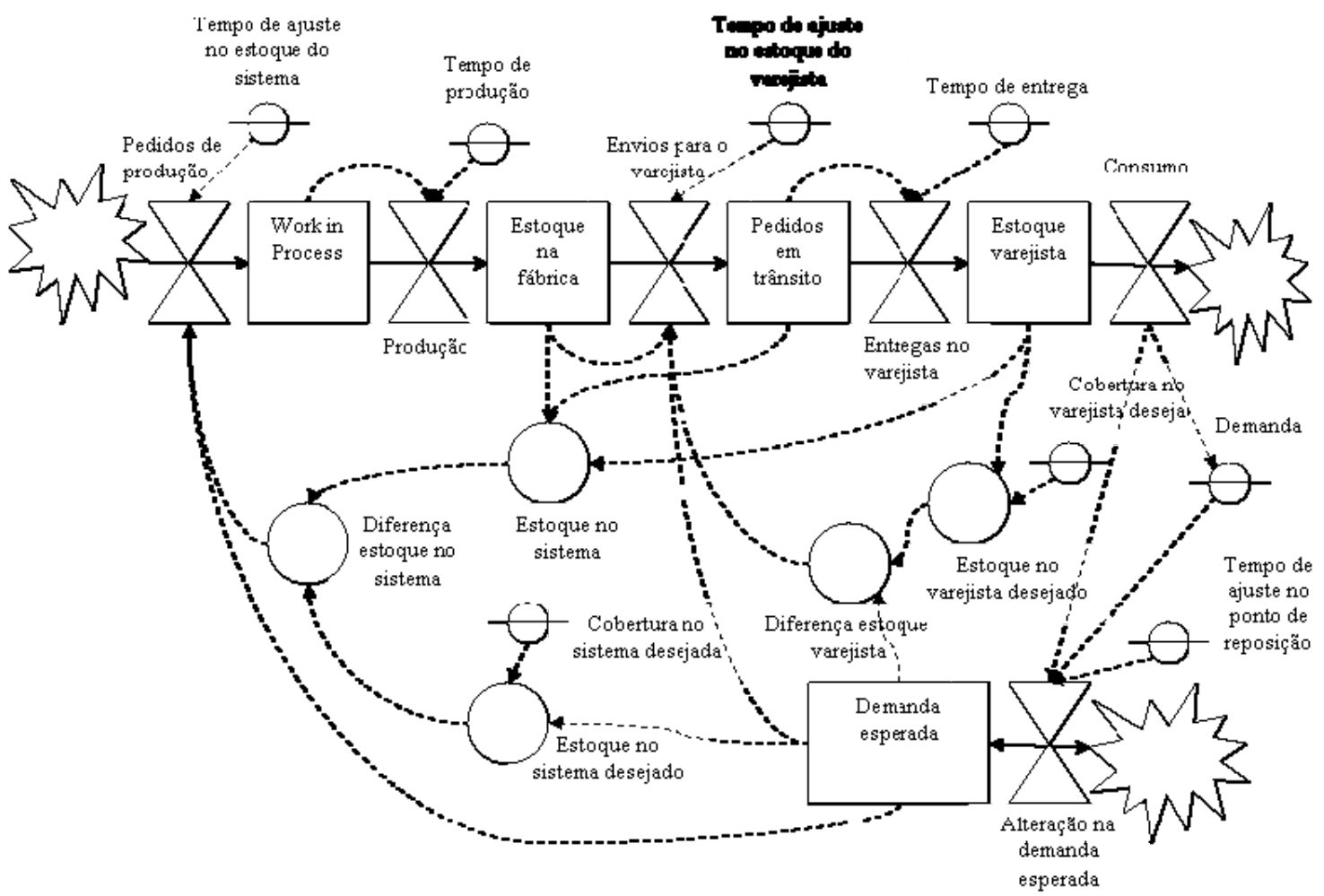

Figura 7 - Diagrama de fluxo do modelo III

No diagrama é possível observar que o fluxo de materiais continua igual ao dos outros modelos, porém o fluxo de informações e tomada de decisões é bem diferente. Não há mais os pedidos esperados e aparece o estoque no sistema, como variável auxiliar, importante para a decisão de pedidos de produção.

Por fim, abaixo são apresentadas as equações do modelo III:

$E V j=E V i+(E i j-C i j) * D T$

$\mathrm{Eij}=\mathrm{ETi} / \mathrm{TE}$

$\mathrm{Cij}=\operatorname{MIN}(\mathrm{Dij}, \mathrm{EVi})$

$\mathrm{DEj}=\mathrm{DEi}+\mathrm{ADij} * \mathrm{DT}$

$\mathrm{ADij}=(\mathrm{Dij}-\mathrm{DEi}) / \mathrm{TA}$

$\mathrm{EDVi}=\mathrm{DEi} * \mathrm{CDV}$

$\mathrm{DEVi}=\mathrm{EDVi}-\mathrm{Evi}$

ENVij $=\operatorname{MAX}(0$, MIN(EFi, DEi + DEVi/TAEV $))$

$E T j=E T i+(E N V i j-E i j) * D T$ 


$$
\begin{aligned}
& \mathrm{EFj}=\mathrm{EFi}+(\mathrm{PRij}-\mathrm{Pij}) * \mathrm{DT} \\
& \mathrm{PRij}=\mathrm{WIPi} / \mathrm{TP} \\
& \mathrm{WIPj}=\mathrm{WIPi}+(\mathrm{PPij}-\mathrm{PRij}) * \mathrm{DT} \\
& \mathrm{PPij}=\mathrm{MAX}(0, \mathrm{DEi}+\mathrm{DESi} / \mathrm{TAES}) \\
& \mathrm{ESi}=\mathrm{EVi}+\mathrm{ETi}+\mathrm{EFi} \\
& \mathrm{DESi}=\mathrm{EDSi}-\mathrm{ESi} \\
& \text { EDSi }=\text { DEi } * \text { CDS }
\end{aligned}
$$

Onde:

$\mathrm{EVi}=$ Estoque no varejista em $\mathrm{i}$

$\mathrm{Eij}=$ Entregas no varejista entre $\mathrm{i}$ e $\mathrm{j}$

$\mathrm{Cij}=$ Consumo no varejista entre $\mathrm{i}$ e $\mathrm{j}$

Dij $=$ Demanda no varejista entre i e $\mathrm{j}$

$\mathrm{ETi}=$ Envios ao varejista em trânsito em i

$\mathrm{TE}=$ Tempo de entrega

DEi $=$ Demanda esperada em $\mathrm{i}$

ADij = Alteração na demanda esperada entre i e j

TA = Tempo de ajuste da demanda esperada

$\mathrm{EDVi}=$ Estoque desejado no varejista em $\mathrm{i}$

$\mathrm{CDV}=$ Cobertura desejada no varejista

$\mathrm{DEVi}=$ Diferença entre estoque desejado e real no varejista em $\mathrm{i}$

ENVij $=$ Envios ao varejista entre i e $\mathrm{j}$

TAEV = Tempo de ajuste estoque varejista

$\mathrm{EFi}=$ Estoque na fábrica em $\mathrm{i}$

PRij $=$ Produção entre i e j

WIPi $=$ Work in process em $\mathrm{i}$

TP = Tempo de produção

PPij = Pedidos de produção entre i e j

TAES = Tempo de ajuste estoque no sistema

DESi $=$ Diferença de estoque no sistema em $\mathrm{i}$

$\mathrm{ESi}=$ Estoque no sistema em $\mathrm{i}$

$\mathrm{EDSi}$ = Estoque desejado no sistema em $\mathrm{i}$

CDS $=$ Cobertura desejada no sistema

\section{IMPLEMENTAÇÃO COMPUTACIONAL}

Com as equações do modelo disponíveis é possível utilizar uma planilha eletrônica para simular o comportamento das variáveis. Existem softwares especializados como o iThink, Stella, Powersim e Vensim, mas foi preferida a utilização de planilha porque o conhecimento do seu uso é mais comum, o que facilita a replicação dos modelos pelos leitores.

Serão analisados dois padrões de demanda utilizando os três modelos. Primeiramente, será observado o efeito de um acréscimo abrupto na demanda, fazendo com que esta se eleve de um patamar de quatro unidades por período para um patamar de oito unidades por período (idêntico ao comportamento da demanda usado no "beer game” (Sterman, 1989)). O outro cenário analisa 
o comportamento das variáveis do modelo com uma demanda probabilística seguindo uma distribuição normal com média 100 e desvio-padrão de 20 unidades.

As simulações foram realizadas ao longo de 100 períodos. No caso da demanda probabilística, os mesmos valores gerados aleatoriamente foram usados nos três modelos para possibilitar uma melhor comparação.

Nos modelos I e II foram usados os mesmos parâmetros:

Tempo de entrega (TE) = $\quad=4$ períodos

Tempo de produção $(\mathrm{TP}) \quad=4$ períodos

Tempo de ajuste na demanda esperada $(\mathrm{TA})=8$ períodos

Tempo de ajuste nos pedidos esperados $(\mathrm{TAP})=4$ períodos

Cobertura desejada no varejista $(\mathrm{CDV})=8$ períodos

Cobertura desejada na fábrica $(\mathrm{CDF})=10$ períodos

Tempo de ajuste do estoque no varejista $(\mathrm{TAEV})=8$ períodos

Tempo de ajuste do estoque na fábrica $(\mathrm{TAEF})=8$ períodos

Com o modelo II, ainda foram analisados dois cenários considerando a porcentagem das informações de demanda na tomada de decisão de pedidos de produção (controlados pela variável X na equação (29)). No primeiro cenário considera-se uma participação de $50 \%$ (X = 0,5) e no segundo cenário uma participação de $100 \%(X=1)$.

No terceiro modelo foram considerados os seguintes parâmetros:

Tempo de entrega (TE) = $\quad=4$ períodos

Tempo de produção $(\mathrm{TP}) \quad=4$ períodos

Tempo de ajuste na demanda esperada $(\mathrm{TA})=8$ períodos

Cobertura desejada no varejista $(\mathrm{CDV})=7$ períodos

Cobertura desejada no sistema $(\mathrm{CDS})=19$ períodos

Tempo de ajuste do estoque no varejista $(\mathrm{TAEV})=9$ períodos

Tempo de ajuste do estoque no sistema $(\mathrm{TAEF})=8$ períodos

Na figura 8 verifica-se o comportamento da demanda, dos pedidos do varejista ao fornecedor e dos pedidos de produção apresentado na simulação utilizando os três modelos. O gráfico no canto superior esquerdo se refere ao modelo I. O gráfico no canto superior direito se refere ao modelo II, utilizando $50 \%$ de compartilhamento de demanda enquanto o gráfico do canto inferior esquerdo se refere ao mesmo modelo II, utilizando, porém, $100 \%$ de compartilhamento de demanda. Por fim, o gráfico no canto inferior direito se refere ao modelo III.

Primeiramente, é possível notar que em todos os modelos observa-se a amplificação na variação dos pedidos, sendo a variação na demanda a menor de todas, se restringindo apenas ao aumento de quatro para oito unidades por período ocorrido no décimo período, enquanto a variação nos pedidos de produção tem a maior variação. A variação dos pedidos ao fornecedor é menor que a dos pedidos de produção, porém maior do que a da demanda. Esta amplificação caracteriza o efeito chicote que ocorre em todos eles. Nota-se, porém que esta variação diminui gradualmente quando se passa do modelo I para o modelo II com 50\% de compartilhamento de informações de demanda, deste para o modelo II com 100\% de compartilhamento de informações de demanda e, por fim, o modelo III é o que apresenta menor variação. Nota-se que tanto os picos diminuem (no modelo I tem período com pedidos de mais de 30 unidades enquanto no modelo III o pico não passa de 20 unidades) como também as oscilações, nota-se que no modelo I temos dois picos e dois vales até a estabilização, enquanto no modelo III temos apenas um pico e um vale quase imperceptível. 


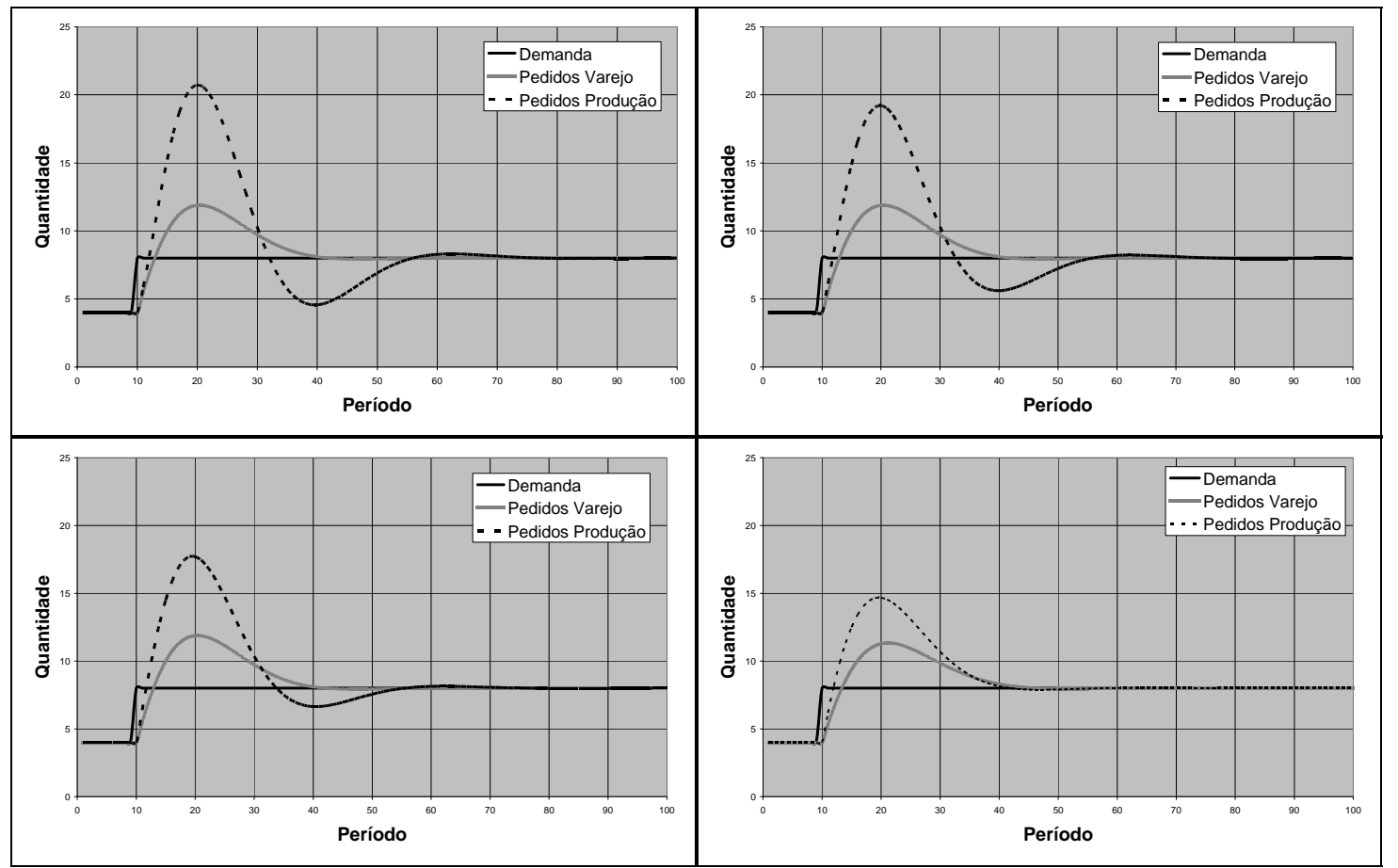

Figura 8 - Demanda, pedidos ao fornecedor e pedidos de produção com degrau de demanda

Na figura 9 pode-se observar o comportamento dos estoques no varejista e no fornecedor para o mesmo padrão de demanda (mudança de patamar instantâneo). A disposição dos gráficos de acordo com o modelo utilizado é a mesma da figura 8. Nota-se que também no caso da variação nos níveis de estoque há uma amplificação, principalmente no modelo I, variação que, porém, é atenuada com a utilização de compartilhamento de informações e apresenta o menor valor no caso da centralização de decisões (modelo I). 


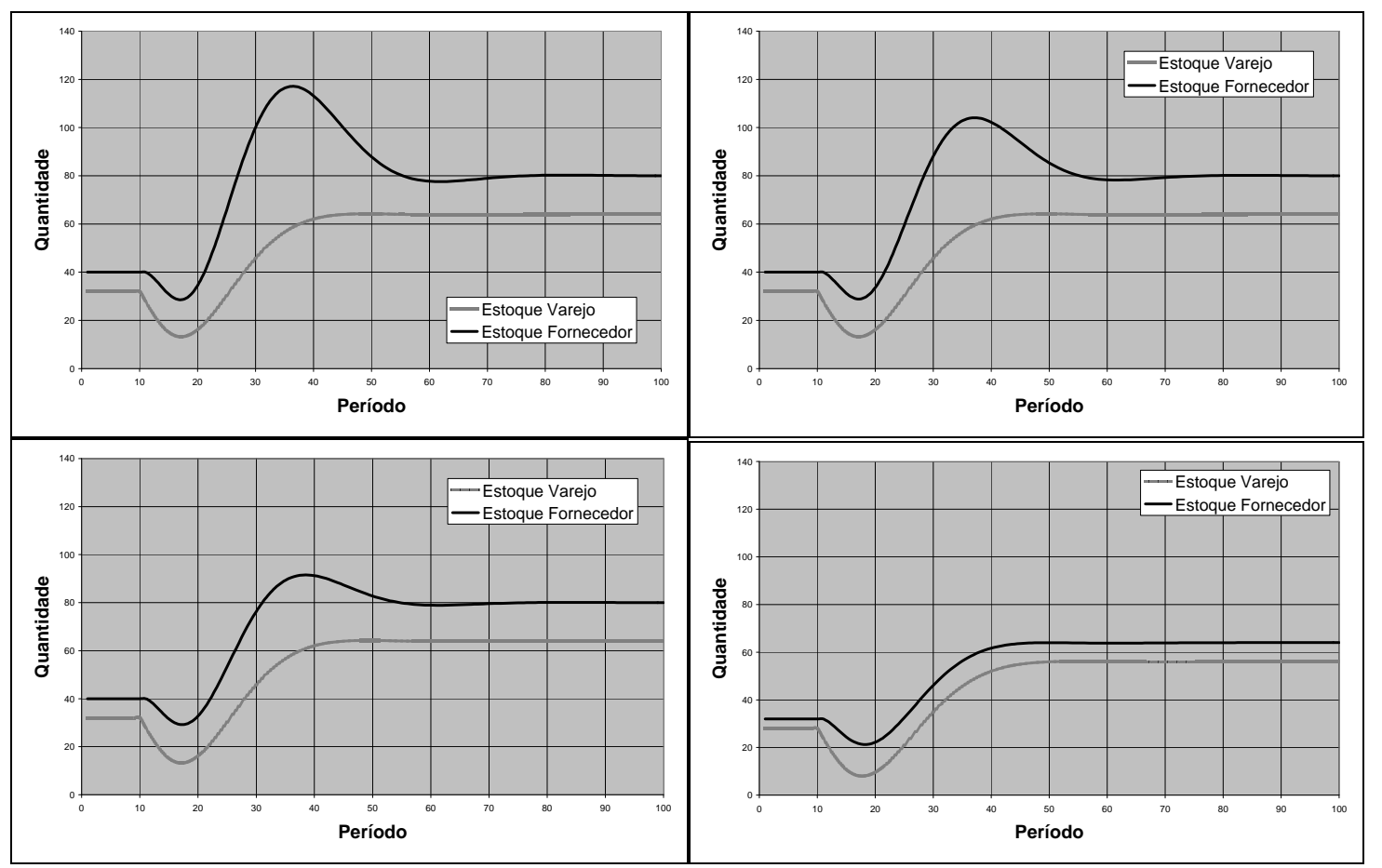

Figura 9 - Comportamento dos estoques no varejista e no fornecedor com degrau de demanda

Na figura 10 são apresentados os comportamentos da demanda, pedidos ao fornecedor e pedidos de produção para o caso em que a demanda varia aleatoriamente de acordo com uma distribuição normal. Os gráficos são dispostos de acordo com os modelos na mesma configuração das figuras anteriores. 


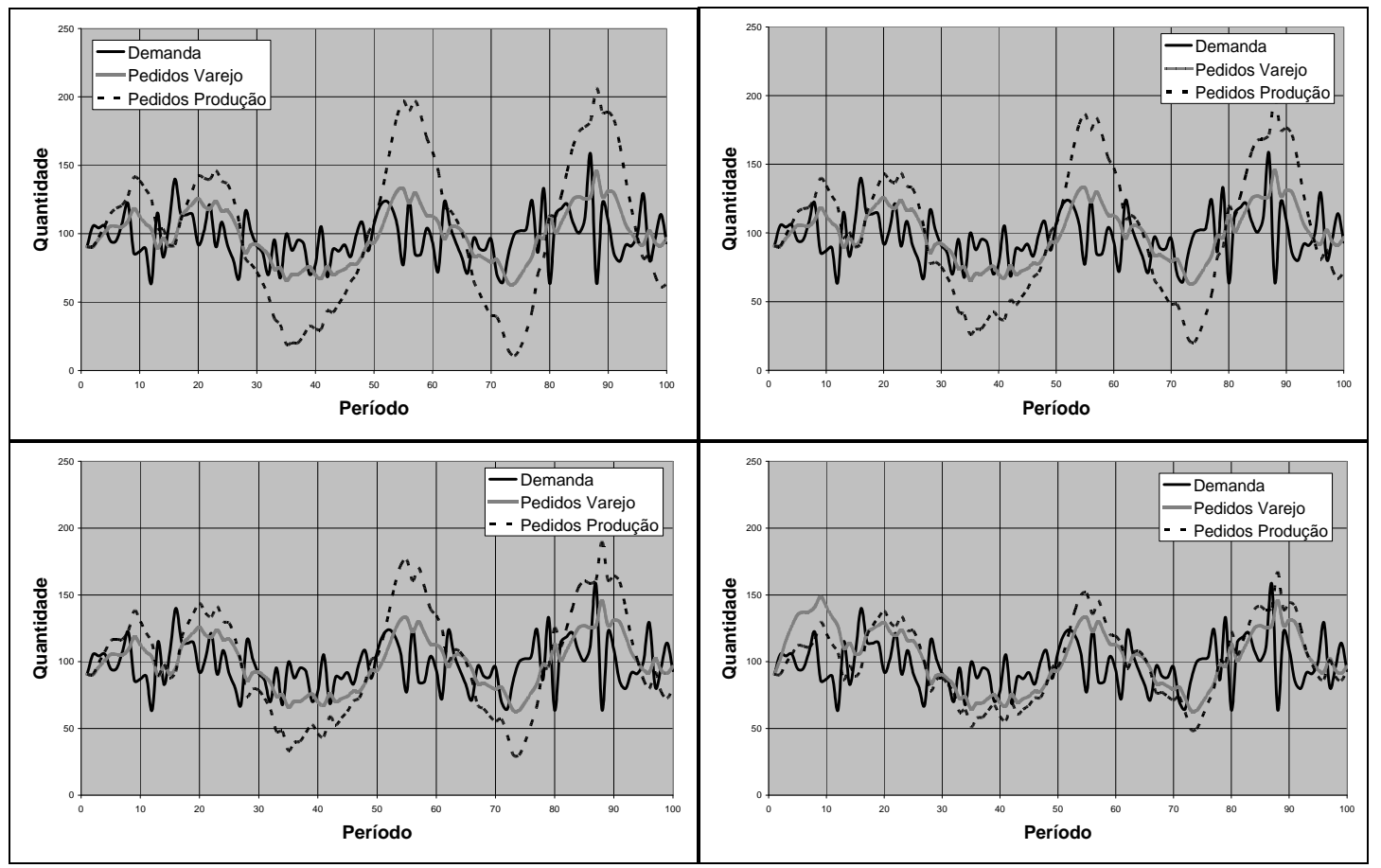

Figura 10 - Comportamento da demanda, demanda esperada, pedidos ao fornecedor e pedidos de produção com demanda aleatória

Também aqui fica bem nítido o efeito chicote e que este efeito se atenua com o compartilhamento de informações e a centralização das decisões de reposição de estoque. Nota-se também que as oscilações formam padrões bem definidos no modelo I. Já no caso da centralização de demanda estes padrões são menos claros. Isto indica que uma das características do efeito chicote é a formação de ciclos viciosos de oscilação, que levam a elevação dos estoques a níveis indesejáveis.

Na figura 11 apresenta-se o comportamento dos estoques no varejista e no fornecedor. Nesta figura pode-se notar também claramente os padrões oscilatórios nos níveis de estoque, que leva a necessidade de aumentar-se as políticas de cobertura de estoques para que não falte produtos nos períodos onde o estoque atinge níveis baixos por causa do efeito chicote.

É possível notar que o comportamento das variáveis se adere ao modo de referência, ou seja, observa-se o comportamento oscilatório dos pedidos e estoques e também a amplificação na variação dos pedidos em relação à demanda. De modo geral, portanto, os modelos simulam bem o efeito chicote. Apesar deste efeito ser menor no caso de compartilhamento de informações e centralização de decisões, ele ocorre nos três modelos. 


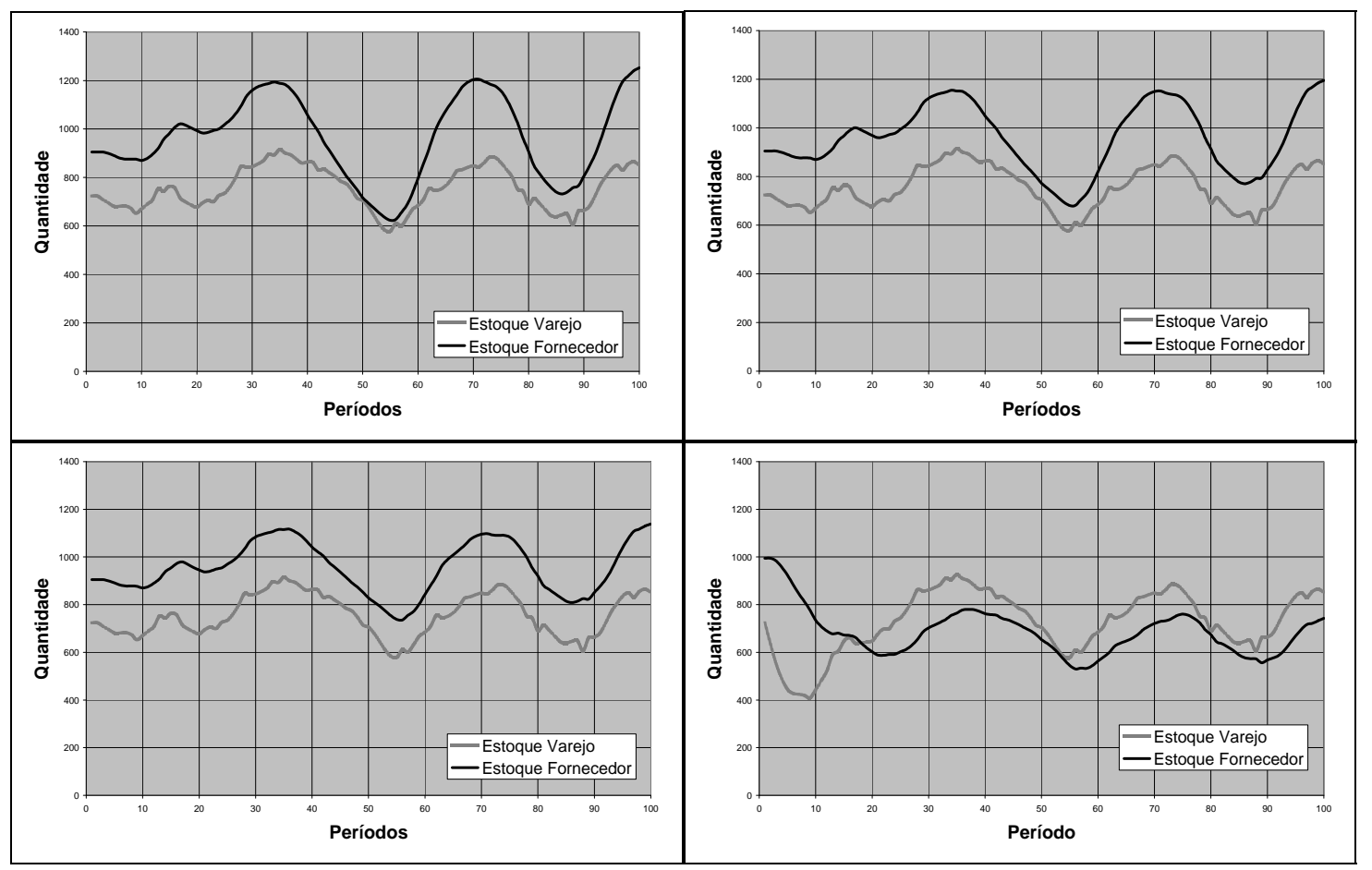

Figura 11 - Comportamento dos estoques com demanda aleatória

\section{Conclusões}

Neste artigo, foi analisado o problema de reposição de estoques em uma cadeia de suprimentos com dois agentes, um varejista e um fornecedor. Foram investigadas as três principais estratégias encontradas na literatura: quando os agentes tomam as decisões de reposição de estoques independentemente e sem compartilhar informações; o fornecedor tem acesso às informações sobre a demanda no ponto de venda, mas as decisões são tomadas independentemente; o fornecedor tem acesso às informações de demanda e estoques no varejista e centraliza as decisões de reposição de estoques. Foi utilizada a simulação por dinâmica de sistemas para criar modelos da cadeia de suprimentos em questão e dos processos de tomada de decisão.

Em todos os modelos foi observada, em maior ou menor grau, a presença do efeito chicote. Este efeito chicote é causado pela sinalização de demanda, uma das causas do efeito chicote apresentadas por Lee et al. (1997). Deve-se notar, portanto, que outras causas não foram analisadas neste trabalho, principalmente as que são expostas em Lee et al. (1997): a disputa dos compradores em momentos de racionamento de fornecimento, a formação de lotes e a especulação de preços. Porém, o efeito chicote causado pela sinalização de demanda é bem representado pelos modelos.

A partir da análise dos resultados das simulações, observam-se indícios de que a centralização de decisões e o compartilhamento de informações contribuem para a redução do efeito chicote e a melhora do desempenho da gestão de estoques na cadeia de suprimentos.

A estratégia de centralização de demanda, característica do programa de colaboração na cadeia de suprimentos conhecido como "vendor managed inventory" (VMI), tem como ponto central a centralização da tomada de decisões por parte do fornecedor sem a participação do varejista. Em muitos casos, o varejista pode se sentir desconfortável em delegar estas decisões para o 
fornecedor, dificultando a implementação prática desta estratégia. Porém, esta mesma estratégia pode ser aplicada em programas com enfoque mais colaborativo, como o CPFR.

Cabe notar que as estratégias aqui analisadas têm enfoque na melhoria da cadeia como um todo, o que pode não ser necessariamente o objetivo dos agentes individualmente. Estes podem estar interessados em melhorar seus desempenhos individuais que podem ser conflitantes entre si, ou seja, o que é bom para o varejista não é bom para o fornecedor e vice-versa.

Para pesquisas futuras recomenda-se a utilização deste método de simulação para analisar outros modelos de cadeia de suprimentos: com mais de dois agentes em série, com um fornecedor e dois varejistas, com um fornecedor e vários varejistas, com dois fornecedores e dois varejistas e outros. Também podem ser analisadas outras estratégias de reposição de estoques não incluídas neste estudo.

\section{Referências Bibliográficas}

Anderson, E., Fine, C. H., Parker, G. (2000). Upstream Volatility in the Supply Chain: The Machine Tool Industry as a Case Study, Production and Operations Management, v.9. n.3, pp.239-260.

Arrow, K. J., Karlin, S.; Scarf., H. (1958). Studies in the Mathematical Theory of Inventory and Production. Stanford University Press, Stanford.

Axsäter, S. (1990). Simple Solution Procedures For a Class of Two-Echelon Inventory Problems, Operations Research, 38, 1, pp. 64-69.

Axsäter, S. (1993). Exact and Aproximate Evaluation of Batch-Ordering Policies for Two-Level Inventory Systems, Operations Research, 41, 4, pp. 777-785.

Clark, A. J., Scarf, H. (1960). Optimal Policies for a Multi-Echelon Inventory Problem, Management Science, 6, 4, pp. 475-490.

De Souza, R., Zice, S., Chaoyang, Liu (2000). Supply Chain Dynamics and Optimization, Integrated Manufaturing Systems, v. 11, n. 5, pp. 348-364.

Disney, S. M., Farasyn, I., Lambrecht, M., Towill, D. R., Van de Velde, W. (2006). Taming the bullwhip effect whilst watching customer service in a single supply chain echelon, European Journal of Operational Research, v. 173, pp. 151-172.

Disney, S. M., Naim, M. M., Towill, D. R. (1997). Dynamic Simulation Modelling for Lean Logistics, International Journal of Physical Distribution and Logistics Management, v. 27, n. 3/4, pp.174-196.

Disney, S. M., Towill, D. R. (2003). Vendor-managed Inventory and Bullwhip Reduction in a Two-level Supply Chain, International Journal of Operations and Production Management, v. 23, n. 6, pp. 625-651.

Forrester, J. (1961). Industrial Dynamics, The M.I.T. Press, Cambridge.

Hong-Minh, S. M., Disney, S. M., Naim, M. M. (2000). The Dynamic of Emergency Transhipment Supply Chains, International Journal of Physical Distribution \& Logistics Management, v. 30, n. 9, pp. 788-815. 
Hosoda, T., Disney, S. M. (2006). The Governing Dynamics of Supply Chains: The Impact of Altruistic Behaviour, Automatica, v. 42, pp. 1301-1309.

Lee, H., Padmanabhan, P., Whang, S. (1997). Information Distortion in a Supply Chain: The Bullwhip Effect, Management Science, 43, 4, pp. 546-558.

Mason-Jones, R., Towill, D.R. (1997). Information enrichment: designing the supply chain for competitive advantage, Supply Chain Management, v. 2, n. 4, pp. 137-148.

Oliveira, C. M. (2004). Análise de políticas de gestão em cadeias de suprimentos por modelos de simulação. Gestão\&Produção, v.11, n.3, pp. 313-329.

Roberts, N., Andersen, D. F., Deal, R. M., Garet, M. S., Shaffer, W. A. (1983). Introdution to Computer Simulation: The System Dynamics Approach, Addison Wesley, Massachusetts.

Silver, E.A.; Peterson, R.; Pyke, D.F. (1998). Decision Systems for Inventory Management and Production Planning. 3 ed., Nova York, Wiley.

Sterman, J. D. (1989). Modeling Managerial Behavior: Misperceptions of Feedback in a Dynamic Decision Making Experiment, Management Science, 35, 3, pp. 321-339.

Sterman, J. D. (2000). Bussiness Dynamics: System Thinking and Modeling for a Complex World. McGraw-Hill, Irwin.

Towill, D. R. (1996). Industrial Dynamics Modelling of Supply Chains, International Journal of Physical Distribution and Logistics Management, v. 26, n. 2, pp. 23-42.

Umeda, S., Zhang, F. (2006). Supply Chain Simulation: Generic Models and Application Examples, Production, Planning and Control, v. 17, n. 2, pp. 155-166.

Wikner, J., Towill, D. R., Nain, M. (1991). Smoothing supply chain dynamics, International Journal of Production Economics, 22, pp. 231-248. 